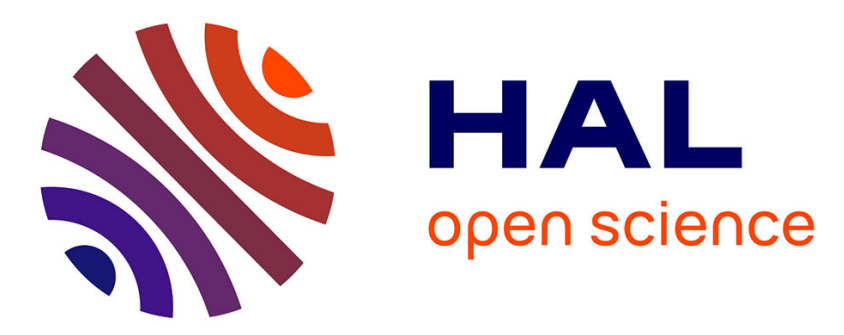

\title{
Desferrioxamine enhances hypoxic ventilatory response and induces tyrosine hydroxylase gene expression in the rat brainstem in vivo
}

\author{
M. V. Nguyen, S. Pouvreau, F. Z. El Hajjaji, M. Denavit-Saubie, J. M.
}

Pequignot

\section{To cite this version:}

M. V. Nguyen, S. Pouvreau, F. Z. El Hajjaji, M. Denavit-Saubie, J. M. Pequignot. Desferrioxamine enhances hypoxic ventilatory response and induces tyrosine hydroxylase gene expression in the rat brainstem in vivo. Journal of Neuroscience Research, 2007, 85 (5), pp.1119 - 1125. 10.1002/jnr.21202 . hal-00188304

\section{HAL Id: hal-00188304 https://hal.science/hal-00188304}

Submitted on 16 Nov 2007

HAL is a multi-disciplinary open access archive for the deposit and dissemination of scientific research documents, whether they are published or not. The documents may come from teaching and research institutions in France or abroad, or from public or private research centers.
L'archive ouverte pluridisciplinaire HAL, est destinée au dépôt et à la diffusion de documents scientifiques de niveau recherche, publiés ou non, émanant des établissements d'enseignement et de recherche français ou étrangers, des laboratoires publics ou privés. 
Desferrioxamine enhances hypoxic ventilatory response and induces tyrosine hydroxylase gene expression in the rat brainstem in vivo.

M.V.C. NGUYEN ${ }^{1,2}$, S. POUVREAU ${ }^{1,2}$, F. Z. EL HAJJAJI ${ }^{1,2}$, M. DENAVIT-SAUBIE ${ }^{1}$, J.M. PEQUIGNOT $^{2}$

1: CNRS UPR 2216, Neurobiologie Génétique et Intégrative, Institut Alfred Fessard, Gif/Yvette, F-91198, France.

2: Université de Lyon, Lyon, F-69003, France ; université Lyon 1, Villeurbanne, F-69622, France; CNRS, UMR 5123, Physiologie Intégrative, Cellulaire et Moléculaire, Villeurbanne, F69622, France.

\section{Corresponding author:}

M.V.C. NGUYEN, mvchuong@yahoo.fr

Laboratoire de Physiologie Intégrative Cellulaire et Moléculaire, UMR CNRS 5123, Bât.

Raphaël Dubois, Université Claude Bernard Lyon1, 69622 Villeurbanne Cedex, France.

Tel : +334724328 83

Fax : +33472431172

\section{Short title:}

Desferrioxiamine and hypoxic responses. 


\begin{abstract}
The iron chelator desferrioxamine (DFO) induces accumulation of the hypoxia-inducible factor (HIF-1), a transcription factor which upregulates genes involved in adaptative responses to hypoxia. This property makes DFO a potential neuroprotector against hypoxic stress. We investigated in rats the effects of DFO on the ventilatory response to mild hypoxic tests and the expression of tyrosine hydroxylase (TH), a target gene of HIF-1. Two protocols were used: one with repeated injections of $50 \mathrm{mg} / \mathrm{kg}$ DFO every 2 days during a 2 week period. This was aimed to define the time-course of the ventilatory responses to a hypoxic test. In the second protocol, rats were given a single injection of $300 \mathrm{mg} / \mathrm{kg}$ DFO. Every day over 4 days the hypoxic ventilatory response was recorded before the animal sacrifice and western-blot analysis of TH in the dorsal brainstem cardiorespiratory area was performed. DFO produced a delayed increase in the hypoxic ventilatory response which appeared in the same time-window as $\mathrm{TH}$ upregulation (2-3 days after the bolus injection of DFO). This delay suggests a genic effect of the drug which improves the ventilatory response to hypoxia.
\end{abstract}

\title{
Keywords
}

Iron-chelator; cardiorespiratory area; ventilation; HIF-1 


\section{Introduction}

The most widespread molecular mechanism of fight against hypoxia is regulated by the transcription factor HIF-1 (Semenza and Wang, 1992). This protein activates several genes making it possible to respond to the hypoxic stress. The inducible sub-unit HIF-1 $\alpha$ is accumulated both in vitro in severe hypoxic conditions (Kroll and Czyzyk-Krzeska, 1998) and in vivo under tolerable hypoxia (Chavez et al., 2000). Rats subjected to a moderate hypoxic challenge show HIF-1 $\alpha$ overexpression in the carotid bodies which are the main peripheral arterial chemoreceptors involved in $\mathrm{O}_{2}$-sensing (Roux et al., 2005). Similar hypoxic conditions elicit a selective accumulation of HIF- $1 \alpha$ mRNA and protein in the dorsal cardiorespiratory area of the brainstem, which integrates the peripheral chemosensory inputs (Pascual et al., 2001). Among a variety of target genes stimulated by hypoxia, the tyrosine hydroxylase $(\mathrm{TH})$ gene is upregulated by HIF-1 (Norris and Millhorn, 1995; Schnell et al., 2003). TH plays a crucial role to improve the supply of oxygen to the brain neural cells by modulating the ventilatory responses to hypoxia (Gonzalez et al., 1981; Hayward, 2001). HIF-1 and TH have been colocalized in catecholaminergic cells, the Type I cells in the carotid body and the medullary neurons in the dorsomedian brainstem (Pascual et al., 2001; Roux et al., 2005). Therefore, the selective HIF-1 overexpression in brainstem cardiorespiratory areas may participate in the ventilatory response to hypoxia.

Desferrioxamine (DFO) is an iron chelator which has been used as a drug to treat iron intoxication (Gillman et al., 1990). Besides their antitoxic effects on iron poisoning, the iron chelators induce the accumulation of HIF-1 (Wang and Semenza, 1993), a property which has been shown to have a neuroprotective effect in cerebral ischemia (Bergeron et al., 2000; Prass et al., 2002). Since DFO induces the accumulation of HIF-1 (Prass et al., 2002) and since HIF-1 activates the expression of genes involved in the reduction of hypoxia (Bernaudin et al., 2002), it was of interest to test the effect of DFO on the ventilatory response to hypoxia. Here, DFO was used as a pharmacological tool to assess the physiological consequences of central accumulation of HIF-1 on ventilatory response to acute tolerable hypoxia. Our hypothesis was 
that DFO might upregulate genes involved in the modulation of ventilatory response to hypoxia, such as the TH gene (Hayward, 2001; Hilaire et al., 2004; Soulage et al., 2003; Soulage et al., 2004; Zanella et al., 2006). Two protocols were used, the first one, with repeated DFO injections, was aimed to study the ventilatory effects of sustained HIF-1 induction. The second protocol was aimed to identify the time-course of upregulation of $\mathrm{TH}$ gene induced with a single injection of DFO and its potential involvement in the functional effects. We found that the DFO increases the ventilatory response to an hypoxic challenge in association with upregulation of $\mathrm{TH}$.

\section{Materials and methods}

Fifty-one male Sprague-Dawley rats $(270-300 \mathrm{~g})$ were used in this study. They were housed individually, exposed to $12 \mathrm{~h}$ light-dark cycle and fed ad libitum with standard diet. Animal studies were carried out in accordance with European Union and French Government animal protection laws.

\section{Pharmacological treatments}

The rats were subjected to the DFO treatment according to two protocols:

Protocol 1: ventilatory effects of repeated injections of DFO. Six rats were given an i.p. injection of DFO (50 mg/kg b.w.) every second day for 2 weeks at D0, D2, D4, D6, D8, D10, D12, and D14 (Table 1). The normoxic ventilatory output and hypoxic ventilatory responses were measured on the day preceding the first injection and then every 4 days (D3, D7, D11, and D15). Six control rats were subjected to the same protocol but were injected the equivalent volume (1 ml i.p.) of saline alone instead of DFO.

Protocol 2: ventilatory and neurochemical effects of a single dose of DFO. The normoxic ventilatory output and the hypoxic ventilatory response were measured just before a single injection of DFO $(300 \mathrm{mg} / \mathrm{kg}, \mathrm{n}=20)$ or saline $(1 \mathrm{ml}, \mathrm{n}=19)$ at D0. One day after the injection, the normoxic ventilatory output and hypoxic ventilatory response were measured in the first group of rats (5 DFO-treated rats and 5 saline rats). These animals were sacrificed immediately 
after recording the ventilatory data (Table 2). The brain was dissected out, frozen in isopenthane and kept at $-80^{\circ} \mathrm{C}$ until biochemical analysis. The same experiments were performed every day for four days (Table 2).

\section{Biochemical analysis}

Tissue preparation. The brainstem area containing the termination site of chemoreceptor afferents (Finley and Katz, 1992; Housley et al., 1987; Housley and Sinclair, 1988) was isolated by cryostat dissection at $-20^{\circ} \mathrm{C}$. The 5 pooled fragments of brainstem were homogenized with 25 strokes in $1 \mathrm{ml}$ of lysis buffer: Tris-HCl $50 \mathrm{mM} \mathrm{pH} 7.5$, Triton X-100 1\%, $\mathrm{NaCl} 100 \mathrm{mM}$, NaF $50 \mathrm{mM}$ and EDTA $5 \mathrm{mM}$, with protease inhibitors (Protease Inhibitor Cocktail, Sigma) and phosphatase inhibitors (Phosphatase Inhibitor Cocktail 2, Sigma) at $4{ }^{\circ} \mathrm{C}$ in Wheaton manual type tissue grinder. The tissue homogenated was centrifuged $15 \mathrm{~min}$ at 14000 $\mathrm{rpm}$ at $4^{\circ} \mathrm{C}$. The supernatant was aliquoted and kept at $-80^{\circ} \mathrm{C}$ until western blotting analysis. Protein concentration was determinated by Bradford assay (Biorad) (Bradford, 1976)

Detection of tyrosine hydroxylase by western blotting. The samples were denatured in Laemmli buffer at $95^{\circ} \mathrm{C}$ for $5 \mathrm{~min}$ and $10 \mu \mathrm{g}$ protein were separated by $8 \%$ SDS-PAGE. SDSPAGE gel was cut into 2 parts at $80 \mathrm{kDa}$ molecular weight. The superior part of gel was stained by coomassie blue to allow verification of equal loading of protein in each well. The lower part was electro-transferred to PVDF immobilon-P membrane (Millipore). Membranes were blocked with 5\% nonfat dry milk in PBS for 2 hours at room temperature and then incubated with the anti-TH (Chemicon) at 1:1000 dilution in 5\% nonfat dry milk/PBS at $4^{\circ} \mathrm{C}$ overnight. After being washed three times for $15 \mathrm{~min}$ with PBS/Tween $0.2 \%$, membranes were incubated with the secondary antibody horseradish peroxidase conjugated at 1:10000 dilution in 5\% nonfat dry milk/PBS for one hour at room temperature. Then membranes were washed again with PBS/Tween $0.2 \%$ three more times. The bound antibodies were visualized using the enhanced chemiluminescence ECL plus reagent (Amersham). 


\section{Ventilatory measurements}

Breathing activity was measured using a barometric method as described by Bartlett and Tenney (1970). In the first protocol, awake unrestrained rats were recorded the day before the first injection (day $-1 ; \mathrm{V}_{1}$ ) and then on day $3,7,11,15\left(\mathrm{~V}_{2}, \mathrm{~V}_{3}, \mathrm{~V}_{4}, \mathrm{~V}_{5}\right.$ ) (Table 1). In the second protocol, ventilation was measured the day before the injection (day-1; $\mathrm{V}_{1}$ ) and then on day 1,2 , 3 and $4\left(\mathrm{~V}_{2}, \mathrm{~V}_{3}, \mathrm{~V}_{4}, \mathrm{~V}_{5}\right)$ (Table 2). The plethysmograph chamber (2.8 1), equipped with a temperature sensor, was connected through a slow leak to a reference chamber, and the pressure difference between the two chambers was measured with a differential pressure transducer (Validyne, DP 103-14) connected to a sine wave carrier demodulator (Validyne, CD 15). The spirogram was stored on a PC computer (CED interface). Calibrations were made during each recording by injecting $0.5 \mathrm{ml}$ of air into the experimental chamber.

The chamber was maintained at $27+/-1^{\circ} \mathrm{C}$ and was permanently flushed with fresh humidified air, except during the data collection sessions, during which time, it was hermetically sealed. The recording sessions of 45 secondes were chosen when the animal was quiet. All measurements were made in quadruplicate, separated by several minute intervals, depending on the degree of activity of the rat. The mean of these four values was taken as the basal (normoxic) ventilation. Each period of baseline breathing was analysed as described previously (Boudinot et al., 2004). A computer program (ACQUIS1 software, BioLogic, Claix, France) measured the duration of inspiration $\left(T_{I}\right)$ and expiration $\left(T_{E}\right)$, ventilatory frequency (fr), tidal volume $\left(\mathrm{V}_{\mathrm{T}}\right)$ and minute ventilation $\left(\mathrm{V}_{\mathrm{E}}\right)$. Mean values were calculated from breaths collected within a minimum period of 15 seconds. The hypoxic test was carried out by flushing the plethysmograph chamber with a mixture of $10 \% \mathrm{O}_{2}$ and $90 \% \mathrm{~N}_{2}$. After the $10 \% \mathrm{O}_{2}$ level was reached inside the chamber, the system was clamped and 4 minutes later the first measurement of hypoxic ventilatory response was performed. Subsequent hypoxic ventilatory response recordings were done in the same way at 7 and 10 minutes after the beginning of hypoxia. 


\section{Statistical analysis}

Statistical analyses were performed with Sigma-Stat v2 software. The effect of DFO on the ventilatory response was evaluated by Two-Way ANOVA using Bonferroni correction. Comparison between saline and DFO treated rats was analysed by Student's paired $t$ test. All results are expressed as the means $\pm \mathrm{SEM}$.

\section{Results}

\section{Kinetics of ventilatory responses to repeated injections of DFO}

\section{Basal measurements}

The basal ventilation measured in normoxia the day preceding the injections and on days $3,7,11$, and 15 was not significantly different between the saline-treated and DFO-treated animals (Fig.1). Furthermore, the body weights of saline controls and DFO-treated animals were not different. Thus, measurements of both basal ventilation and body growth failed to reveal any obvious effect of DFO in normoxic conditions.

\section{Effects of repeated injections of DFO on the hypoxic ventilatory response}

In contrast to normoxia, the short exposure to hypoxia revealed different ventilatory behaviours between the saline controls and DFO-treated rats (Fig.1). In both groups of animals, the hypoxic test elicited a rapid ventilatory response. However, the hypoxia-induced hyperventilation was higher in DFO-treated rats during the first week of treatment (D3, D7). There was a significant interactive effect between DFO treatment and O2 level $(\mathrm{F}[1,10]=$ $6.572, \mathrm{p}<0.05)$. The mean measurements $(\mathrm{n}=6 \mathrm{DFO} ; \mathrm{n}=6$ saline) of ventilatory output on $\mathrm{D} 3$ were $146.5+/-4$ vs. $120.5+/-3.5 \mathrm{ml} / \mathrm{min} / 100 \mathrm{~g}$ b.w., and $137.4+/-7$ vs. $115.3+/-4.6$ $\mathrm{ml} / \mathrm{min} / 100 \mathrm{~g}$ b.w on $\mathrm{D} 7$, in saline controls and DFO-treated rats, respectively. The effects of DFO faded during the second week of treatment. Although still apparent due to increased VT $(\mathrm{P}<0.05)$, the difference in hypoxic ventilatory response between saline controls and DFOtreated rats did not reach the significant level because the respiratory frequency was slightly reduced. 


\section{Ventilatory and biochemical responses to a single injection of DFO}

\section{Basal measurements}

The basal ventilation measured in normoxia on the day before the injection and the four following days was not different between the saline controls and the DFO-treated animals (data not shown). Thus, like after repeated injections, a single dosage of DFO was unable to modify significantly the normoxic ventilatory output in rats.

Effects of a single injection of DFO on the hypoxic ventilatory response

The ventilatory values recorded over the four days following a single DFO injection were averaged (Fig 2) to get an overall view of the functional effects of DFO. The mean ventilatory response to the hypoxic test was characterized by significant increases of minute ventilation $(+8.8 \% \mathrm{p}<0.05)$, breathing frequency $(+11.2 \% \mathrm{p}<0.05)$, and tidal volume $(+11.7 \%$ $\mathrm{p}<0.05$ ). During the course of the hypoxic test, the hypoxic ventilatory responses did not differ between the saline controls and the DFO-treated rats during the first 4 minutes of hypoxia. The minute ventilation became significantly different after 7 minutes of hypoxia (Fig 2A), while every ventilatory parameter was significantly affected after 10 minutes (Fig 2A, B, C).

Evolution of the hypoxic ventilatory response during the four days following a single injection of DFO

By comparing every day the hypoxic response (at 10 min exposure) over the four days following a single DFO injection, the DFO-treated rats showed a larger tidal volume than the saline controls on the second day (D2) (Fig 3). This alteration in ventilatory response to hypoxia was followed by an enhanced frequency response to hypoxia at D3. Consequently, a single injection of DFO produced an overall increase in ventilatory output by $6.8 \%(\mathrm{p}<0.05)$.

Biochemical effects of DFO on tyrosine hydroxylase expression in the dorsal cardiorespiratory area of the brainstem

Because the activation of catecholaminergic neurons in the dorsal cardiorespiratory area of the brainstem may be a factor involved in regulation of the hypoxic ventilatory response (Pépin et al., 1996; Schmitt et al., 1994), we tested the DFO-induced changes in TH protein expression. There was an increase of the protein level in the DFO-treated rats as compared to 
the saline controls. This increase produced following iron chelation occurred 2 days after the drug injection and was thus concomitant with the early change in hypoxic ventilatory response observed in the DFO-treated rats.

\section{Discussion}

The present data show that DFO did not affect significantly basal breathing under normoxic conditions. However, it induced a subtle stimulatory influence on the ventilatory response to hypoxia and a concomitant overexpression of $\mathrm{TH}$ in the cardiorespiratory area of the dorsal brainstem. The time-course of this effect, with a delayed onset, suggests the upregulation of subsequent downstream pathways.

\section{Technical considerations:}

In protocol 1, repeated injections of DFO were performed in order to determine the kinetics of functional effects. The dose of DFO used in this investigation represents $10 \%$ of the LD50 and is high enough to elicit a significant reduction of the iron content in the brain (Ward et al., 1995). The large delay between each measurement was chosen to preclude the long-term ventilatory facilitation induced by repeated hypoxic bouts (Mitchell et al., 2001) and the effects of stress due to the drug injection were avoided by performing no ventilatory measurement on the days of drug injection. This protocol showed a ventilatory effect on the hypoxic response, which appeared only 3 days after the first injection, suggesting a cascade of gene inductions. Therefore, using a single drug injection in the second protocol was aimed to characterize in the same animal the kinetics of DFO-induced ventilatory response and TH expression as a HIF-1 target gene. The dose of DFO injected as a bolus $(300 \mathrm{mg} / \mathrm{kg})$ has been found to produce the accumulation of HIF-1 in the brain and the upregulation of its target gene EPO as shown by the increased levels of EPO protein in vivo and EPO mRNA in brain neurons and astrocytes (Bernaudin et al., 2000; Prass et al., 2002). 


\section{Ventilation}

The present data showed an increase in ventilatory response to hypoxia after both DFO treatments. This increase was subtle, delayed and transient. Most of the studies investigating the neuroprotective effects of DFO have been performed in animal models subjected to lifethreatening hypoxic situations such as stroke, brain injury, or middle cerebral arterial occlusion (Mu et al., 2005; Nakamura et al., 2004; Sharp et al., 2001). These studies have shown that the extent of tissue lesion was reduced by DFO treatment.

Instead of pathological conditions, our study was performed with a brief tolerable hypoxic test in an attempt to reveal the physiological mechanisms of action of the iron chelator. Under such a moderate challenge, DFO induced a reinforcement of the hypoxic ventilatory response which remained subtle, presumably because the animal was not in a situation of critical life-threatening stress. In humans, upregulation of HIF target genes induced by a pathological inhibition of HIF degradation is associated with a slightly enhanced hypoxic ventilatory response similar to that elicited by acclimatization to the high altitude hypoxia (Smith et al., 2006). In the present study, the improved ventilatory hypoxic response appeared 2-3 days after the DFO bolus injection and persisted during 1 week of repeated DFO injections. Despite repeated injections, the ventilatory responses returned progressively to the control level, suggesting a compensatory mechanism that improved the oxygen supply to the brain independently of pulmonary ventilation.

Using the transgenic mouse line $\mathrm{Tg} 21$ which overexpresses constitutively human EPO in the brain, Soliz et al. (2005) demonstrated that EPO, a target gene of HIF, controls ventilation under hypoxic conditions both at the central and peripheral level, the brainstem and the carotid body respectively. It is thus possible that the effects of DFO were mediated by modulation of peripheral arterial chemosensitivity and/or brainstem respiratory control. However, Daudu et al. (2002) reported that DFO did not modify the peripheral chemosensory activity because the drug did not penetrate in vitro the type I glomus cells which sense the changes in oxygen arterial blood pressure. One explanation for the delayed effect can be that DFO is acting on respiratory centers instead of peripheral arterial chemoreceptors. The delay can be due to remodeling of the 
central chemosensory pathway resulting from gene induction. This delay explains why the ventilatory response to hypoxia was not observed after a 1 day DFO perfusion in man (Ren et al., 2000).

The present data provide evidence that DFO was able to upregulate the expression of $\mathrm{TH}$ in the dorsal brainstem area which is involved in the cardiorespiratory responses to hypoxia. Although the ventrolateral brainstem is involved in respiratory control and contains catecholaminergic neurons, the present study focused on the dorsomedian brainstem as the primary site of termination and integration of chemosensory afferent fibers. Noticeably, the study by Soliz et al. (2005) performed in Tg21 mice showed alterations in norepinephrine metabolism which were restricted to the dorsomedian brainstem, while the ventrolateral medulla of transgenic mice did not show changes in $\mathrm{TH}$ activity compared to the wild strain. Interestingly the DFO-induced upregulation of $\mathrm{TH}$ occurred in the same time-window as the increased ventilatory response to the DFO injection. This result correlates well with the increase of TH expression found in the same braimstem area under hypoxia (Dumas et al., 1996; Pascual et al., 2001). The role of TH in the control of ventilatory output has been described in the neuronal network which controls ventilation (Bianchi et al., 1995). Its effect is relevant both in the carotid body (Gonzalez et al., 1981) and in the central chemosensory areas, where TH is overexpressed under long term hypoxia (Schmitt et al., 1994; Dumas et al., 1996). Catecholaminergic neural cell groups in the brainstem have been reported to modulate the hypoxic ventilatory response (Hayward, 2001; Hilaire et al., 2004; Soulage et al., 2003; Soulage et al., 2004; Zanella et al., 2006). Alteration of catecholaminergic metabolism in the dorsomedian brainstem has been implicated in the stimulation of breathing by brain EPO. Thus the DFO-induced increase of $\mathrm{TH}$ in the present study could be associated to the improved ventilatory response to hypoxia. Conversely, the finding that DFO had no effect on basal ventilation indicates that the drug per se has no direct effect on ventilation but acts on the mechanisms which control the acclimatization to hypoxia.

So far the neuroprotective effects of DFO have been studied mostly in animal models of cerebral ischemic stress and have been ascribed to the activation of EPO through stabilization of 
HIF-1 (Freret et al., 2006; Mu et al., 2005; Prass et al., 2002). HIF-1 is the transcriptional factor responsible for the induction of TH under hypoxia (Kroll et al., 1998) and a large array of hypoxia-sensitive genes (Semenza, 2001). HIF-1 and TH have been colocalized in the brainstem cardiorespiratory area in hypoxic rats (Pascual et al., 2001). Here, the transient TH overexpression does not exclude the consecutive upregulation of further genes (e.g., VEGF) activated by HIF-1 and responsible for other ways of improved oxygen supply independent of ventilatory response.

In conclusion, DFO induces an improved physiological response to a tolerable hypoxic stress, which could be mediated by the overexpression of $\mathrm{TH}$ as a neuromodulator of central breathing control. 


\section{Acknowledgement}

This work was supported by CNRS, ACI BDP157, and BDP0223, E.C grant "Brainstem genetics" QLG2-CT-2001-01467, ENVIRHONALP and Direction Générale de l'armement Contract DSP/STTC00/34/077. We wish to thank Dr. Bradley Launikonis (Rush University, Chicago, IL) for kindly reviewing the English style of the manuscript and Dr Artur Foutz for his scientific advice. 


\section{REFERENCES}

Bartlett D, Jr., Tenney SM. 1970. Control of breathing in experimental anemia. Respir Physiol 10:384-395.

Bergeron M, Gidday JM, Yu AY, Semenza GL, Ferriero DM, Sharp FR. 2000. Role of hypoxiainducible factor-1 in hypoxia-induced ischemic tolerance in neonatal rat brain. Ann Neurol 48:285-296.

Bernaudin M, Bellail A, Marti HH, Yvon A, Vivien D, Duchatelle I, Mackenzie ET, Petit E. 2000. Neurons and astrocytes express EPO mRNA: oxygen-sensing mechanisms that involve the redox-state of the brain. Glia 30:271-278.

Bernaudin M, Tang Y, Reilly M, Petit E, Sharp FR. 2002. Brain genomic response following hypoxia and re-oxygenation in the neonatal rat. Identification of genes that might contribute to hypoxia-induced ischemic tolerance. J Biol Chem 277:39728-39738.

Bianchi AL, Denavit-Saubie M, Champagnat J. 1995. Central control of breathing in mammals: neuronal circuitry, membrane properties, and neurotransmitters. Physiol Rev 75:1-45.

Boudinot E, Emery MJ, Mouisel E, Chatonnet A, Champagnat J, Escourrou P, Foutz AS. 2004. Increased ventilation and $\mathrm{CO} 2$ chemosensitivity in acetylcholinesterase knockout mice. Respir Physiol Neurobiol 140:231-241.

Bradford MM. 1976. A rapid and sensitive method for the quantitation of microgram quantities of protein utilizing the principle of protein-dye binding. Anal Biochem 72:248-254.

Chavez JC, Agani F, Pichiule P, LaManna JC. 2000. Expression of hypoxia-inducible factor-1 alpha in the brain of rats during chronic hypoxia. J Appl Physiol 89:1937-1942.

Daudu PA, Roy A, Rozanov C, Mokashi A, Lahiri S. 2002. Extra- and intracellular free iron and the carotid body responses. Respir Physiol Neurobiol 130:21-31. 
Dumas S, Pequignot JM, Ghilini G, Mallet J, Denavit-Saubie M. 1996. Plasticity of tyrosine hydroxylase gene expression in the rat nucleus tractus solitarius after ventilatory acclimatization to hypoxia. Brain Res Mol Brain Res 40:188-194.

Finley JC, Katz DM. 1992. The central organization of carotid body afferent projections to the brainstem of the rat. Brain Res 572:108-116.

Freret T, Valable S, Chazalviel L, Saulnier R, Mackenzie ET, Petit E, Bernaudin M, Boulouard M, Schumann-Bard P. 2006. Delayed administration of deferoxamine reduces brain damage and promotes functional recovery after transient focal cerebral ischemia in the rat. Eur J Neurosci 23:1757-1765.

Gillman A, Rall RW, Nies AS, Taylor P, eds. Goodman and Gilman's. 1990. The Pharmacological Basis of Therapeutics. New York: Pergamon Press. pp. 1592-1614.

Gonzalez C, Kwok Y, Gibb J, Fidone S. 1981. Physiological and pharmacologic effects on TH activity in rabbit and cat carotid body. Am J Physiol 240:R38-43.

Hayward LF. 2001. Evidence for alpha-2 adrenoreceptor modulation of arterial chemoreflexes in the caudal solitary nucleus of the rat. Am J Physiol Regul Integr Comp Physiol 281:R1464-1473.

Hilaire G, Viemari JC, Coulon P, Simonneau M, Benvegut M. 2004. Modulation of the respiratory rhythm generator by the pontine noradrenergic A5 and A6 groups in rodents. Respir Physiol Neurobiol 143:187-197.

Housley GD, Martin-Body RL, Dawson NJ, Sinclair JD. 1987. Brain stem projections of the glossopharyngeal nerve and its carotid sinus branch in the rat. Neuroscience 22:237250.

Housley GD, Sinclair JD. 1988. Localization by kainic acid lesions of neurones transmitting the 
carotid chemoreceptor stimulus for respiration in rat. J Physiol 406:99-114.

Kroll SL, Czyzyk-Krzeska MF. 1998. Role of H2O2 and heme-containing O2 sensors in hypoxic regulation of tyrosine hydroxylase gene expression. Am J Physiol 274:C167174.

Mitchell GS, Baker TL, Nanda SA, Fuller DD, Zabka AG, Hodgeman BA, Bavis RW, Mack KJ, Olson EB Jr. 2001. Intermittent hypoxia and respiratory plasticity. J Appl Physiol $90: 2466-2475$.

Mu D, Chang YS, Vexler ZS, Ferriero DM. 2005. Hypoxia-inducible factor 1alpha and erythropoietin upregulation with deferoxamine salvage after neonatal stroke. Exp Neurol 195:407-415.

Nakamura T, Keep RF, Hua Y, Schallert T, Hoff JT, Xi G. 2004. Deferoxamine-induced attenuation of brain edema and neurological deficits in a rat model of intracerebral hemorrhage. J Neurosurg 100:672-678.

Norris ML, Millhorn DE. 1995. Hypoxia-induced protein binding to O2-responsive sequences on the tyrosine hydroxylase gene. J Biol Chem 270:23774-23779.

Pascual O, Denavit-Saubie M, Dumas S, Kietzmann T, Ghilini G, Mallet J, Pequignot JM. 2001. Selective cardiorespiratory and catecholaminergic areas express the hypoxiainducible factor-1alpha (HIF-1alpha) under in vivo hypoxia in rat brainstem. Eur J Neurosci 14:1981-1991.

Pépin JL, Levy P, Garcin A, Feuerstein C, Savasta M. 1996. Effects of long-term hypoxia on tyrosine hydroxylase protein content in catecholaminergic rat brainstem areas: a quantitative autoradiographic study. Brain Res 733:1-8.

Prass K, Ruscher K, Karsch M, Isaev N, Megow D, Priller J, Scharff A, Dirnagl U, Meisel A. 2002. Desferrioxamine induces delayed tolerance against cerebral ischemia in vivo and 
in vitro. J Cereb Blood Flow Metab 22:520-525.

Ren X, Dorrington KL, Maxwell PH, Robbins PA. 2000. Effects of desferrioxamine on serum erythropoietin and ventilatory sensitivity to hypoxia in humans. J Appl Physiol 89:680686.

Roux JC, Brismar H, Aperia A, Lagercrantz H. 2005. Developmental changes in HIF transcription factor in carotid body: relevance for $\mathrm{O} 2$ sensing by chemoreceptors. Pediatr Res 58:53-57.

Schmitt P, Soulier V, Pequignot JM, Pujol JF, Denavit-Saubie M. 1994. Ventilatory acclimatization to chronic hypoxia: relationship to noradrenaline metabolism in the rat solitary complex. J Physiol 477:331-337.

Schnell PO, Ignacak ML, Bauer AL, Striet JB, Paulding WR, Czyzyk-Krzeska MF. 2003. Regulation of tyrosine hydroxylase promoter activity by the von Hippel-Lindau tumor suppressor protein and hypoxia-inducible transcription factors. J Neurochem 85:483491.

Semenza GL. 2001. Hypoxia-inducible factor 1: control of oxygen homeostasis in health and disease. Pediatr Res 49:614-617.

Semenza GL, Wang GL. 1992. A nuclear factor induced by hypoxia via de novo protein synthesis binds to the human erythropoietin gene enhancer at a site required for transcriptional activation. Mol Cell Biol 12:5447-5454.

Sharp FR, Bergeron M, Bernaudin M. 2001. Hypoxia-inducible factor in brain. Adv Exp Med Biol 502:273-291.

Smith TG, Brooks JT, Balanos GM, Lappin TR, Layton DM, Leedham DL, Liu C, Maxwell PH, McMullin MF, McNamara CJ, Percy MJ, Pugh CW, Ratcliffe PJ, Talbot NP, Treacy M, Robbins PA. 2006. Mutation of von Hippel-Lindau tumor suppressor and 
human cardiopulmonary physiology. Plos Med 3:1178-1185.

Soulage C, Perrin D, Cottet-Emard JM, Pequignot JM. 2003. A6 noradrenergic cell group modulates the hypoxic ventilatory response. Adv Exp Med Biol, 536:481-487.

Soulage C, Pascual O, Roux JC, Denavit-Saubié M, Pequignot JM. 2004. Chemosensory inputs and neural remodeling in carotid body and brainstem catecholaminergic cells. Adv Exp Med Biol, $551: 53-58$.

Wang GL, Semenza GL. 1993. Desferrioxamine induces erythropoietin gene expression and hypoxia-inducible factor 1 DNA-binding activity: implications for models of hypoxia signal transduction. Blood 82:3610-3615.

Ward RJ, Dexter D, Florence A, Aouad F, Hider R, Jenner P, Crichton RR. 1995. Brain iron in the ferrocene-loaded rat: its chelation and influence on dopamine metabolism. Biochem Pharmacol 49:1821-1826.

Zanella S, Roux JC, Viemari JC, Hilaire G. 2006. Possible modulation of the mouse respiratory rhythm generator by A1C1 neurones Respir Physiol Neurobiol 153:115-202. 


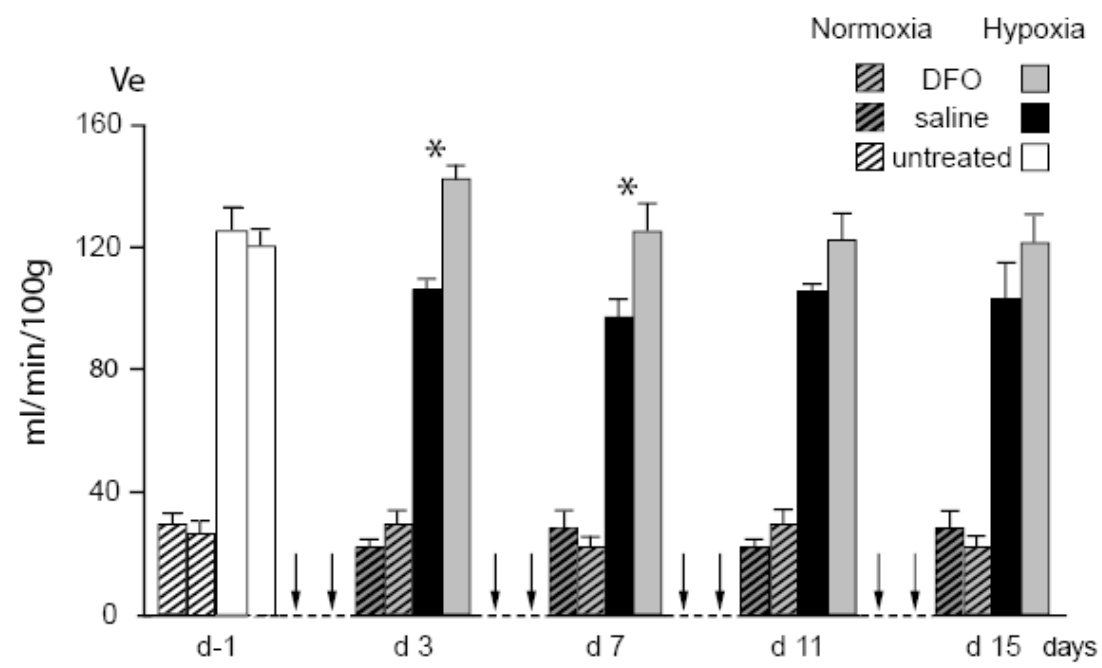

Figure 1: Increased ventilatory response to a hypoxic test in rats treated with repeated injections of DFO. Minute ventilation (Ve) was recorded under normoxia (hatched bars) and hypoxia (10 $\min 10 \% \mathrm{O}_{2}$ and $90 \% \mathrm{~N}_{2}$ ) the day before the first injection (D-1) (white bars). The ventilatory recordings were performed during treatment on days $3,7,11$ and 15 (black bars: saline controls, grey bars: DFO-treated rats). The arrows indicate injections. * Significant difference of hypoxic response between DFO-treated and control animals $(p<0.05)$. 

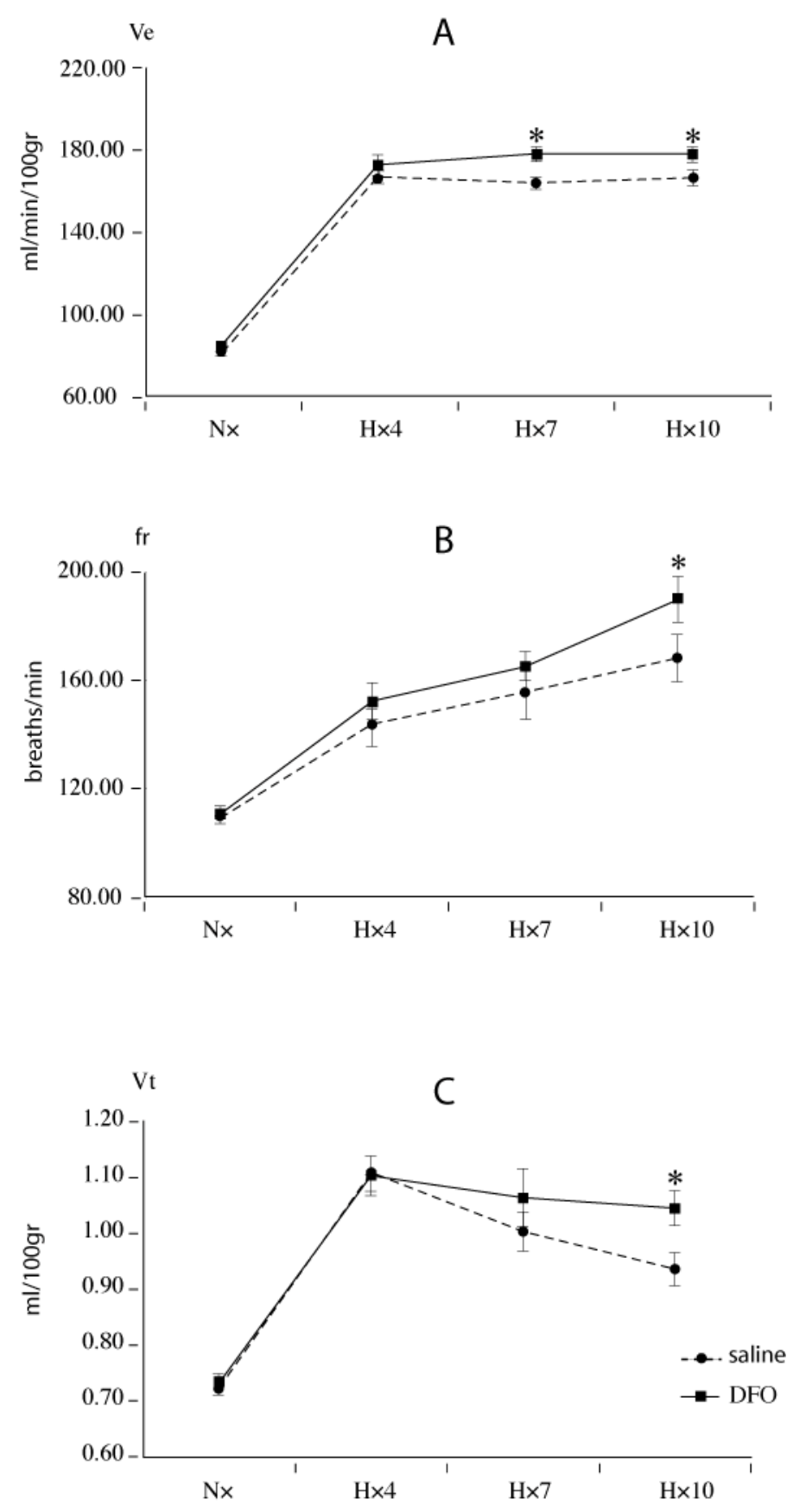

Figure 2: Comparison of ventilatory responses to a hypoxic test in rats treated with a single injection of DFO. Ventilatory parameters were recorded under normoxia $(\mathrm{Nx})$ and after 4 minutes $(\mathrm{Hx} 4), 7$ minutes $(\mathrm{Hx} 7)$ and 10 minutes $(\mathrm{Hx} 10)$ of hypoxia. Data are means of the recordings performed over the four days following the injection. A) Mean ventilation (Ve), B) Mean frequency (fr), C) Mean tidal volume (Vt). * Significant difference of hypoxic response between DFO-treated and control animals $(\mathrm{p}<0.05)$. 

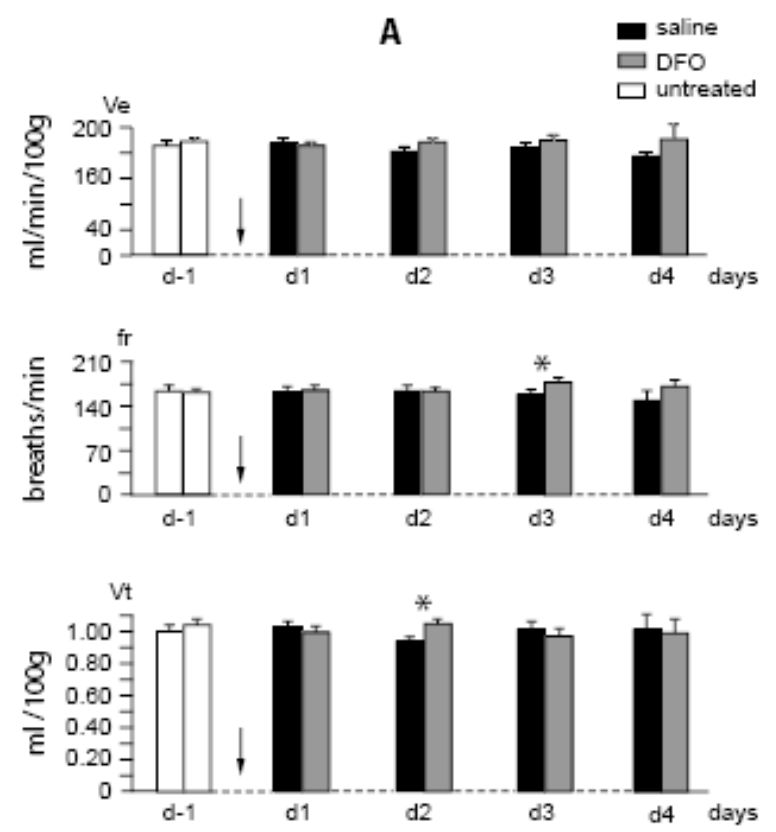

B

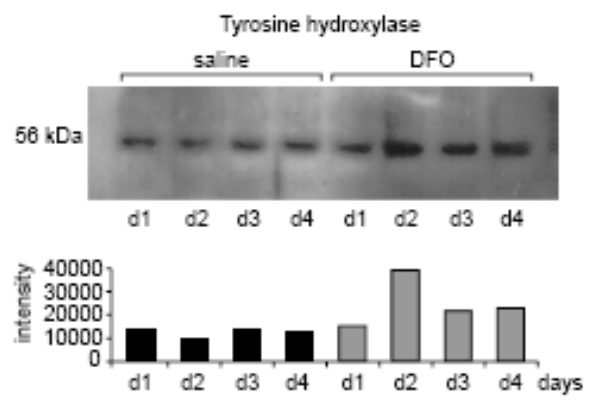

Figure 3:

A. Evolution of the ventilatory response to a hypoxic test after a single injection of DFO. Minute ventilation (Ve), frequency (fr) and tidal volume (Vt) were recorded under hypoxia (10 $\min 10 \% \mathrm{O}_{2}$ and $90 \% \mathrm{~N}_{2}$ ) the day before DFO injection (D-1) (white bars) and the four following days (black bars: saline controls, grey bars: DFO-treated rats). The arrow indicates the injection. * Significant difference of hypoxic response between treated and control animals $(\mathrm{p}<0.05)$

B. Evolution of tyrosine hydroxylase expression after a single injection of DFO. Western blot analysis of TH in the dorsal brainstem cardiorespiratory areas of control and DFO-treated rats sacrificed each day after the last respiratory recording from D1 to D4. Quantification of Western blot intensity is expressed as arbitrary units. 


\begin{tabular}{|c|c|c|c|c|c|c|c|c|c|c|c|c|c|c|c|c|c|}
\hline days & -1 & 0 & 1 & 2 & 3 & 4 & 5 & 6 & 7 & 8 & 9 & 10 & 11 & 12 & 13 & 14 & 15 \\
\hline \multirow{2}{*}{ Control $\mathrm{n}=6$} & $\mathrm{~V}_{1}$ & & & & $\mathrm{~V}_{2}$ & & & & $\mathrm{~V}_{3}$ & & & & $\mathrm{~V}_{4}$ & & & & $\mathrm{~V}_{5}$ \\
\cline { 2 - 14 } & & Sal. & & Sal. & & Sal. & & Sal. & & Sal. & & Sal. & & Sal. & & Sal. & \\
\hline \multirow{2}{*}{ Treated $\mathrm{n}=6$} & $\mathrm{~V}_{1}$ & & & & $\mathrm{~V}_{2}$ & & & & $\mathrm{~V}_{3}$ & & & & $\mathrm{~V}_{4}$ & & & & $\mathrm{~V}_{5}$ \\
\cline { 2 - 13 } & & DFO & & DFO & & DFO & & DFO & & DFO & & DFO & & DFO & & DFO & \\
\hline
\end{tabular}

Table 1

\begin{tabular}{|r|c|c|c|c|c|c|}
\hline days: & -1 & 0 & 1 & 2 & 3 & 4 \\
\hline Control $n=5$ & $V_{1}$ & Saline & $V_{2} S$ & & & \\
\hline Treated $n=5$ & $V_{1}$ & DFO & $V_{2} S$ & & & \\
\hline & & & & & & \\
\hline Control $n=4$ & $V_{1}$ & Saline & $V_{2}$ & $V_{3} S$ & & \\
\hline Treated $n=5$ & $V_{1}$ & DFO & $V_{2}$ & $V_{3} S$ & & \\
\hline & & & & & & \\
\hline Control $n=5$ & $V_{1}$ & Saline & $V_{2}$ & $V_{3}$ & $V_{4} S$ & \\
\hline Treated $n=5$ & $V_{1}$ & DFO & $V_{2}$ & $V_{3}$ & $V_{4} S$ & \\
\hline & & & & & & \\
\hline Control $n=5$ & $V_{1}$ & Saline & $V_{2}$ & $V_{3}$ & $V_{4}$ & $V_{5} S$ \\
\hline Treated $n=5$ & $V_{1}$ & DFO & $V_{2}$ & $V_{3}$ & $V_{4}$ & $V_{5} S$ \\
\hline
\end{tabular}

Table 2 